\title{
1 Dark diversity reveals importance of biotic resources and competition for plant diversity across broad environmental gradients
}

3 Camilla Fløjgaard $^{1}$, Jose W. Valdez ${ }^{1}$, Lars Dalby ${ }^{1}$, Jesper Erenskjold Moeslund ${ }^{1}$, Kevin K. Clausen ${ }^{1}$,

4 Rasmus Ejrnæs ${ }^{1}$, Meelis Pärtel ${ }^{2}$, Ane Kirstine Brunbjerg $^{1}$ *

$5 \quad{ }^{1}$ Department of Bioscience - Kalø, Aarhus University, Grenåvej 14, 8410, Rønde, Denmark

$6{ }^{2}$ Department of Botany, Institute of Ecology and Earth Sciences, University of Tartu, Lai 40, Tartu, 51005,

7 Estonia

$8 \quad *$ Corresponding authors

9 Email: camf@bios.au.dk, akb@bios.au.dk 


\section{Abstract}

Species richness is the most commonly used metric to quantify biodiversity. However, examining dark diversity, the group of missing species which can potentially inhabit a site, can provide a more thorough understanding of the processes influencing observed biodiversity and help evaluate the restoration potential of local habitats. So far, dark diversity has mainly been studied for specific habitats or largescale landscapes while less attention has been given to variation across broad environmental gradients or as a result of local conditions and biotic interactions. In this study, we investigate the importance of local environmental conditions in determining dark diversity and observed richness in plant communities across broad environmental gradients. We use the ecospace concept to investigate how abiotic gradients (defined as position), availability of biotic resources (defined as expansion), spatiotemporal extent of habitats (defined as continuity), as well as species interactions through competition, relate to these biodiversity measures. Position variables were important for both plant richness and dark diversity, some with quadratic relationships, e.g., plant richness showing a unimodal response to soil fertility corresponding to the intermediate productivity hypothesis. Competition represented by community mean Grime $\mathrm{C}$ showed a negative correlation with plant richness. Besides position, organic carbon was the most important variable for dark diversity, indicating that in late succession habitats such as forests and shrubs, dark diversity is generally low. The importance of Grime $\mathrm{C}$ indicate that intermediate disturbance, such as grazing, may facilitate higher species richness and lower dark diversity. Comparing various biodiversity metrics and their influencing factors might reveal important drivers of biodiversity changes and result in better conservation decision-making.

\section{Keywords}

Beal's smoothing, community completeness, conservation, regional species pool, species co-occurrence, vascular plants

\section{Introduction}

The global biodiversity crisis represents one of the most critical challenges in the $21^{\text {st }}$ century, with up to one million plant and animal species facing extinction and accelerating declines despite numerous international agreements and management responses (Tittensor et al., 2014, Butchart et al., 2010, Díaz et al., 2019). Achieving conservation goals and prioritizing efforts requires appropriate metrics to quantify biodiversity and identify the factors driving the declines. The most commonly used measure is observed species richness which traditionally depends on visual surveys to count the individual species. Although observed diversity can provide valuable insights into the richness of species within a given site, it does not account for the absent part of the species pool that could potentially inhabit that site based on suitable environmental conditions and biogeographic history, i.e., the dark diversity (Pärtel et al., 2011). Identifying 
this part of the biodiversity can provide a more thorough understanding of the processes influencing biodiversity and help evaluate the restoration potential of local habitats (Lewis et al., 2016).

In contrast to observed diversity, dark diversity focuses on the portion of diversity potentially able to occur in a particular habitat type. This metric can provide insight into the determinants of missing species by helping us understand why certain species are missing more often than others and the characteristics of sites typically missing many species that could potentially exist there. Quantifying dark diversity patterns, in combination with observed diversity patterns, may allow researchers to better understand the mechanisms and processes acting on individual populations or entire communities (Pärtel et al., 2017b). So far, the potential value of dark diversity to guide conservation and restoration planning has been demonstrated for mammals (Estrada et al., 2018), sharks (Boussarie et al., 2018), and fungi (Pärtel et al., 2017b, Pärtel et al., 2017a). However, most of its potential as a conservation tool has been realized in plants and has been used in conservation prioritization of plant communities across Europe (Moeslund et al., 2017) and determining the relationship between dark diversity and the invasion potential of alien species in semi-natural grasslands (Bennett et al., 2016). Dark diversity has also proven valuable in understanding plant diversity patterns, such as determining that vascular plant dark diversity across Europe follows a latitudinal gradient (Ronk et al., 2015). So far, the plant traits likely to increase a species' probability of being part of the dark diversity include stress intolerance, tall, adaption to low light and nutrient levels, and producing fewer and heavier seeds (Riibak et al., 2017, Moeslund et al., 2017, Riibak et al., 2015). Understanding the ecological processes governing plant dark diversity is important since vascular plants can not only predict biodiversity across environmental gradients and broad taxonomic realms, but are also related to the occurrence of regionally redlisted species of other taxa (Brunbjerg et al., 2018). Furthermore, plants are bio-indicators of their abiotic environment and anthropogenic impact (Bartelheimer and Poschlod, 2016), and they form the living and dead organic carbon pools and biotic surfaces that are the niche space for all other taxonomic groups (Brunbjerg et al., 2017b). Nevertheless, as a relatively new concept, more research is required to establish its full potential and to understand the ecological processes governing dark diversity across plant communities.

Dark diversity can also be used to derive community completeness, a relativized biodiversity index, which has been proposed as a valuable tool for facilitating biodiversity comparisons irrespective of regions, ecosystems, and taxonomic groups (Pärtel et al., 2013). The community completeness index can be defined, in general terms, as the proportion of species from the regional species pool which have dispersed to and established at a site after abiotic and biotic filtering (Pärtel et al., 2013). Since patterns in observed species richness may mimic patterns in dark diversity (e.g., exhibit a strong latitudinal gradient) (Aning, 2017, Ronk et al., 2015, Pärtel et al., 2011, Zobel, 1997), community completeness can provide a better measure of biodiversity as it accounts for the variation in species pool size and expresses biodiversity on a relative scale (Pärtel et al., 2013). For instance, in previous studies, completeness exhibited no relationships to latitudinal gradients, but strong relations to anthropogenic disturbance (higher completeness in areas with lower 
disturbance) for fungi (Pärtel et al., 2017b), plants (Ronk et al., 2015, Ronk et al., 2016), and birds (Cam et al., 2000). Comparing the environmental processes influencing these biodiversity measurements can provide valuable information for better prioritization of resources and understanding patterns of biodiversity. However, despite observed species richness and its determining factors being relatively established, dark diversity and its completeness counterpart are new methodologies, and as such, have not been well investigated and the factors influencing them are not fully understood.

Since biodiversity varies greatly across ecosystems and are highly dependent on the habitat and region of interest, dark diversity and completeness aims to reconcile the role of local (biotic interactions, abiotic filters, dispersal, stochastic events) and large-scale processes (species diversification and historic migration patterns) underlying biodiversity patterns (Pärtel, 2014, Pärtel et al., 2011). Determining the set of species which can theoretically inhabit a site, the species pool, is typically estimated using species co-occurrence patterns with Beal's smoothing which assumes species with shared ecological requirements and biogeographical history will have similar likelihoods of being present at a particular site (de Bello et al., 2012, Lewis et al., 2016, Beals, 1984, Münzbergová and Herben, 2004, McCune, 1994). This approach also assumes to account for prevalent competitive interaction which is a major factor influencing species occurrence patterns (de Bello et al., 2012, Cornell and Harrison, 2014), especially in plant communities (Riibak et al., 2015). Despite co-occurrence being successfully implemented as a proxy for species ecological requirements and competition, this assumption has not been examined. Another potential issue is that many ecological processes are scale dependent with different spatial scales inherently including varying amounts of environmental heterogeneity (Scott et al., 2011). However, most of dark diversity research has ignored the variability between types of habitats and have mostly been restricted to narrow sets of variables and specific habitats (Riibak et al., 2015) or largescale landscapes (Ronk et al., 2016, Ronk et al., 2015), with no studies examining how dark diversity varies across large environmental gradients or the importance of local conditions and biotic interactions. One way to consider the roles these factors play in dark diversity measurements can be provided with the recently developed ecospace framework which recognizes the influence of environmental gradients (defined as position), availability of biotic resources (defined as expansion), and the spatiotemporal extent of habitats (defined as continuity) in determining biodiversity (Brunbjerg et al., 2017b). This framework can help us better quantify and determine the different aspects that each contribute and how they relate to the various diversity metrics.

In this study, we investigate the importance of local environmental conditions that determine dark diversity and completeness in plant communities across broad environmental gradients and compare these measures with the observed richness. We use the ecospace concept to investigate how abiotic condition, biotic resources and spatiotemporal processes relate to these biodiversity measures. To examine the assumption that co-occurrence can be a proxy for competitive exclusion, we used the community mean of plant competitive scores (Grime, 1979) to quantify the importance of local interspecific competition for 
114

115

116

117

118

119

120

121

122

123

124

125

126

127

128

129

130

131

132

133

134

135

136

137

138

139

140

141

142

143

144

establishment of species. We discuss how dark diversity can contribute with new aspects for informed conservation and management.

\section{Materials and Methods}

\section{Study sites}

Our data stems from Biowide, a nationwide survey of biodiversity in Denmark (Brunbjerg et al., 2017a). A total of 130 study sites $(40 \mathrm{~m} \times 40 \mathrm{~m}$ ) were evenly distributed across five geographic regions in Denmark with a minimum distance of $500 \mathrm{~m}$ between sites (Fig 1a). Each site is sampled in four $5 \mathrm{~m}$ circle plots (Fig 1b). Sampling was designed with the purpose of evaluating the ecospace framework, stating that biodiversity varies according to abiotic conditions, build-up and diversification of organic resources and spatio-temporal continuity (Brunbjerg et al., 2017b). The sites were stratified according to environmental gradients and 30 sites were allocated to represent cultivated habitats and 100 sites to natural and semi-natural habitats. The cultivated subset was stratified according to major land-use types and the natural subset was stratified according to soil fertility, soil moisture and successional stage. Saline and fully aquatic habitats were deliberately excluded, but temporarily inundated depressions, as well as wet mires and fens were included. The final set of 24 environmental strata consisted of the following six cultivated habitat types: Three types of fields (rotational, grass leys, set aside) and three types of plantations (beech, oak, spruce). The remaining 18 strata were natural and semi-natural habitats, constituting all factorial combinations of: fertile and infertile; dry, moist, and wet; open, tall herb/scrub, and forest. All 24 strata were replicated in each of the five geographical regions. For the purpose of the present study, we exclude all agricultural fields, resulting in a dataset of 115 sites. All field work and sampling was conducted in accordance with Responsible Research at Aarhus University and Danish law. For a thorough description of site selection and stratification procedures, see Brunbjerg et al. (2017a).

\section{Data}

\section{$\underline{\text { Plant species richness }}$}

Vascular plant species richness was inventoried by trained botanists during the summer 2014 and spring 2015 to account for variations in phenology. The reference dataset of plant inventories in $5 \mathrm{~m}$ circles from the national monitoring program (Danish Nature Agency, 2016) was also inventoried by trained botanists. We removed all subspecies, hybrids, variations, and neophytes (i.e. species that are not considered a natural part of the vegetation given their history and dispersal ability, see appendix tables 6-8 in(Buchwald et al., 2013). Plant species nomenclature was obtained from the species checklist Denmark database from https://allearter-databasen.dk to match the two datasets and account for different synonyms. 


\section{Explanatory variables}

We used the ecospace concept to investigate how abiotic condition (i.e., position), biotic resources (i.e., expansion), and spatiotemporal extent of habitats (i.e., continuity) explain plant richness, dark diversity and community completeness (Table 1). The position variables included in the model were soil moisture index (SMI) and soil fertility index (SFI). For each site SFI represents the predicted value from the best linear model (of all sites) of site mean Ellenberg N (plant-based bioindication of nutrient status; (Ellenberg et al., 1991)) as a function of soil Ca, leaf N, leaf NP and soil type. We calculated a soil moisture index for each site using the predicted values from the best linear model (of all sites) of mean Ellenberg F (plant-based bioindication of soil moisture; Ellenberg et al., 1991) as a function of mean precipitation in 2001-2010 (10 $\mathrm{km} \times 10 \mathrm{~km}$ grid resolution) and measured site soil moisture (trimmed mean of 16 measures pr. site taken with a FieldScout TDR 300 Soil Moisture Meter in May 2016) (Brunbjerg et al., in prep). Position also included soil $\mathrm{pH}$ measured on 4 pooled soil samples from 0-10 $\mathrm{cm}$ depth and light measured as light intensity (Lux) using HOBO Pendant ${ }^{\circledR}$ Temperature/Light $8 \mathrm{~K}$ Data Loggers installed at the ground as detailed in Brunbjerg et al. (2017a). The expansion variables included: 1) Bare soil percent coverage as a subjective estimate, 2) Litter mass ( $\mathrm{g} / \mathrm{m}-2$ of four litter samples within a $21 \mathrm{~cm} \times 21 \mathrm{~cm}$ frame pr. site). The four samples from each site were pooled, taken to the laboratory, dried $\left(60^{\circ}\right.$ for 48 hours) and mass $(\mathrm{g} / \mathrm{m}-2)$ was registered, 3) Soil organic matter as a percentage of the $0-10 \mathrm{~cm}$ soil core that was categorized as organic soil, and 4) soil organic carbon as $\%$ soil $\mathrm{C}$ in $0-10 \mathrm{~cm}$ soil layer $(\mathrm{g} / \mathrm{m}-2$ average of four soil samples taken in each site) as described in Brunbjerg et al. (2017a). Expansion also included structural heterogeneity from variation in the digital elevation model (DEM6) $(40 \mathrm{~cm} \times 40 \mathrm{~cm}$ resolution) from the digital surface model (40 $\mathrm{cm} \times 40 \mathrm{~cm}$ resolution) to create a grid representing the above-ground vegetation height. From this the structural heterogeneity was calculated as the sum of variability in the shrub layer and canopy layer, measured as the variance of the 90th percentile for returns $>3 \mathrm{~m}$ within the site reflecting the variability of the height of mainly trees and the variance of the 90th percentile for returns $30 \mathrm{~cm}-3 \mathrm{~m}$ reflecting the variability of the height of the shrub layer (Brunbjerg et al., in prep). Landscape characteristics were represented by two co-variables: 1) share of intensive fields within a $500 \mathrm{~m}$ buffer and 2) the share of natural habitats in a $1 \mathrm{~km} \times 1 \mathrm{~km}$ grid from a national mapping, interpolated using Spline in ArcGIS 10.2.2 (weight 0.5, number of points 9, (Ejrnæs et al., 2014)). Temporal continuity was estimated as time since major land use change within the $40 \mathrm{~m} \times 40 \mathrm{~m}$ site. For each site, a temporal sequence of aerial photos and historical maps was inspected starting with the most recent photos (photos from 2014, 2012, 2010, 2008, 2006, 2004, 2002, 1999, 1995, 1968, 1954, 1945) and ending with historical maps reflecting land use in the period 18421945. Temporal continuity (the year in which a change could be identified) was reclassified into a numeric 4level variable: 1: 1-14 years, 2: 15-44 years, 3: 45-135 years, 4: >135 years (Brunbjerg et al., 2017a). Lastly, to examine the importance of species interactions and the assumption that co-occurrence can be a proxy for competitive exclusion, we quantified local interspecific competition by calculating an index for the intensity 
180

181

182

183

184

185

186

187

188

189

190

191

192

193

194

195

196

197

198

199

200

201

202

203

204

205

206

207

208

209

210

211

212

213

of plant competition (Grime C) using the community mean plant competitive score (Grime, 1979) which is thought to reflect plant species' adaptation to interspecific competition (Grime et al., 2014). The original CS-R species strategies were recoded into numeric mean site C values (Ejrnæs and Bruun, 2000).

\section{Data analysis}

\section{Regional pool, dark diversity and completeness}

All statistical analyses were performed in R version 3.5.3 (R Core Team, 2019). To calculate regional pools, we used $5 \mathrm{~m}$ circle plots of observed plant species from both datasets. We did not include species-poor plots, i.e., those with less than five observed species, i.e., resulting in 448 plots from Biowide and 52362 plots from the reference data set. The regional pool was calculated using Beals index (Beals, 1984), as recommended by (Lewis et al., 2016). The Beals index represents the probability that a particular species will occur within a given site based on the assemblage of co-occurring species (Beals, 1984, Münzbergová and Herben, 2004, McCune, 1994). We calculated Beals index using the 'beals' function in the 'vegan' package (Oksanen et al., 2017). The threshold for including a particular species in the regional species pool is recommended to be the $5^{\text {th }}$ percentile of the Beals index value for the species in question (Gijbels et al., 2012, Ronk et al., 2015). Preceding the calculation of each threshold, the lowest Beals index value among plots with occurrence of the species in question was identified, and all plots having values below that minimum were not considered.

Analyses were done at the site level $(n=115)$ by creating a site regional pool combining the four plot regional pools at each site. Observed species in the site, but not included in the regional pools $(n=2)$ were added to the regional pools to ensure that site regional pool included all observed species. Then, dark diversity was calculated for each plot as the difference between the regional pool and the observed species richness (Pärtel et al., 2011) and completeness was calculated following Pärtel et al. (2013) using the formula In(observed richness/dark diversity). Because dark diversity is relative based on habitat types and may not be suitable for comparison across habitats (Scott et al., 2011), completeness is suggested as possible alternative (Pärtel et al., 2013). Completeness should have been suitable for investigations across habitat types, but in this study we found that completeness was highly correlated with observed species richness (Figure 2). Therefore, we obtained a dark diversity measure corrected for habitat differences by using the residuals of a model of dark diversity as a function of the habitat type, which we termed Bio-stratum, a classification of the sites using all inventoried species data, i.e., plants, fungi, insects, etc., resulting in eight classes spanning gradients in succession (Early, Late), moisture (Wet, Dry) and nutrients (Rich, Poor). The habitat types explained $51 \%$ of the variation in dark diversity.

\section{$\underline{\text { Statistical analyses }}$}

Soil $\mathrm{pH}$, litter mass, organic carbon, organic matter and shrub and canopy height variation were logtransformed and all explanatory variables were standardized. We conducted model selection by first testing 
214 for multicollinearity, which could affect p-values and model validity using the Variance Inflation Factor

215 (VIF). We then removed canopy height variation and organic matter resulting in a maximum VIF of 2.9. The

216 remaining variables were used as explanatory variables (linear terms) in a set of generalized linear models

217 (GLM) using the MASS package (Venables and Ripley, 2013) with Poisson distribution for the count data

218 for dark diversity and plant richness, and normal distribution for residual dark diversity. However, since

219 models for plant richness were over-dispersed we chose negative binomial models for this response instead.

220 To allow for non-linear relationships for position variables corresponding to the intermediate disturbance

221 hypothesis (Townsend et al., 1997, Connell, 1978) and intermediate productivity hypothesis(Fraser et al.,

222 2015), we used AIC (Burnham and Anderson, 2002) to evaluate if inclusion of quadratic terms for the

223 variables SMI, SFI, Light, soil $\mathrm{pH}$ and bare soil improved the model fit, in which case relevant quadratic

224 terms were added. Subsequently, we checked the parameter estimates against plausible ecological

225 hypotheses (Table 1) and excluded ecologically implausible responses (Burnham and Anderson, 2002). We

226 then dropped remaining variables sequentially based on AIC using the lme4 package (Bates et al., 2007). The

227 final models were tested for over-dispersion and evaluated by visual inspection of residual plots and for

228 spatial autocorrelation using Moran's I in the ape package (Paradis et al., 2004).

\section{Results}

230 We found a total of 580 species of vascular plants in the 115 sites spanning from open habitats to shrubs and late succession forests. The species richness per site ranged from 8 to 127 species and dark diversity ranged from 84 to 243 species. Completeness and plant species richness were highly positively correlated, whereas dark diversity was less correlated with plant species richness (Figure 2). The final models explained between 14 and $65 \%$ of the variation in dark diversity, residual dark diversity and species richness (Table 2). We found position variables to be important for dark diversity and plant species richness (Figure 3, 5). SMI invoked a unimodal response in dark diversity but a bimodal response in species richness. We observed a positive effect of SFI and soil $\mathrm{pH}$ on dark diversity and unimodal relationships with species richness. Light had a negative linear and unimodal relationship with dark diversity and species richness, respectively. No position variables were found to be important for the residual dark diversity, as would be expected. Organic carbon was important for all measured responses with a linear negative relationship across response variables (Figure 3-5). Grime $\mathrm{C}$ had a positive linear relationship with dark diversity and a negative linear relationship with plant species richness (Figure 3,5), while natural landscapes had a linear negative relationship with residual dark diversity (Figure 4).

\section{Discussion}

Completeness, thought to be less dependent on habitat types (Pärtel et al., 2013), was highly correlated 
diversity aspects. Therefore, we explore residual dark diversity, another measure independent of habitat type. Position variables were important for both plant richness and dark diversity. Not surprisingly, once differences between habitat types were accounted for, i.e. residual dark diversity, the position variables were no longer significant. Plant richness was highest at intermediate conditions of soil fertility and $\mathrm{pH}$, corresponding to the intermediate productivity hypothesis, which states that few species can tolerate the environmental stresses at low productivity and a few highly competitive species dominate at high productivity (Fraser et al., 2015). Species richness increased with $\mathrm{pH}$, possibly corresponding to the generally large regional species pool in calcareous habitats, and aligns with previous research indicating that plant diversity has a strong positive association with soil pH in temperate and boreal regions (Pärtel, 2002, Pärtel et al., 2004). The unimodal relationship between dark diversity and soil moisture may be due to communities at the extremes being more distinct than communities at intermediate soil moisture, i.e., specific adaptations for waterlogged and very dry soil are required (Ernst, 1990). Therefore, fewer coincidental species may appear in these extreme habitats compared to habitats of intermediate moisture, resulting in a low estimated regional pool and lower dark diversity at the extremes.

Regarding the expansion variables, variation in shrub height was negatively correlated with dark diversity and positively correlated with species richness, indicating that vegetation heterogeneity (and resulting local variation in light, temperature, etc.) increases the establishment and survival of species (Stein et al., 2014). Previous research has shown that shrub height can increase species richness in competitive environments as variance in heights can ameliorate conditions to neighboring plants and cause biomass to be distributed in vertical space, thereby reducing competition for space (Bråthen and Lortie, 2016). We also found bare soil had a negative effect on species richness as would be expected since more bare soil will by definition have fewer observed individuals and species. The only expansion variable to influence both dark diversity measures (and the only expansion variable influencing the residual dark diversity) and species richness was soil organic carbon, which had a negative relationship with both dark diversity and species richness. Previous studies have also indicated that native and exotic richness is lower with higher soil organic carbons (Perelman et al., 2007). These results may be due to temporal continuity and the effect on the various successional levels on the accumulation of soil organic carbon. For example, more established and complete communities (e.g., old forests) accumulate greater organic carbon but exhibit lower species diversity (Garnier et al., 2004). This may also be true for species poor acidic habitats like mires, bogs and heaths, which were represented in this study. Competition plays a large role with early successional species able to modify the environment through rapid growth and inhibit the success of species currently present, while later stage communities are typically composed of the most competitive species and replace earlier succession species (Connell and Slatyer, 1977). Therefore, the potential species that can inhabit the area may be restricted by competitive species. This competitive advantage inherit in late successional communities results in greater dark diversity, corresponding to our result that Grime $\mathrm{C}$ is important for plant dark 
282

283

284

285

286

287

288

289

290

291

292

293

294

295

296

297

298

299

300

301

302

303

304

305

306

307

308

309

310

311

312

313

314

315

316

diversity. The positive effect of Grime $\mathrm{C}$ on dark diversity indicates that there are more species missing from communities dominated by competitive species. The effect on plant species richness was opposite, likely because dominant competitive species exclude other species, thereby reducing the overall plant species richness. It seems that competition does not affect the species pool, otherwise suitable species would become locally extinct due to dominant species, but they still remain in dark diversity and can be restored if competition is controlled (e.g. disturbance). Spatial continuity, in this case natural landscape, was only important for residual dark diversity, whereas competition was not important. One possibility is that the habitat types account not only for variation in position but also the inherent competitive strategies of the species in the habitat types e.g., late successional stages dominated by competitive species, possibly explaining why competition is not important for residual dark diversity. Natural landscapes may decrease dark diversity by influencing local processes, i.e., landscapes with high nature density are likely to have a higher local pool of species, increased dispersal, increased species survival, metapopulation structures, and less negative edge-effects of intense land use (Brunbjerg et al., 2017b). Another explanation why natural landscape was only significant for residual dark diversity may be that the effect of habitat type and position variables it is large and masks all other effects in both dark and observed diversity. This effect is only visible when these variables are accounted for.

This study shows that there are many different methodologies to measure biodiversity, and that they contribute with different aspects to better understand drivers of diversity, with their applicability depending on the desired objectives and goals. For example, if looking at the effects of organic carbon on species richness one may conclude that carbon capture and storage may lead to loss of species richness, however dark diversity indicates that carbon storage could increase habitat completeness. Just like there are dozens of different ways to measure species diversity (Lyashevska and Farnsworth, 2012), there are also many ways to calculate dark diversity. Besides the typical co-occurrence measure, dark diversity can also be calculated as community completeness (Pärtel et al., 2013), based on ecological requirements (Lewis et al., 2016, Bello et al., 2016) or species distribution (Bello et al., 2016), and probabilistic measurements such as hypergeometric distributions (Carmona et al., 2019). Here, we compared dark diversity and completeness, but found that completeness was highly correlated with observed species richness. We therefore advocate to compare and analyze different diversity measures as both dark diversity and completeness are still relatively new metrics. Furthermore, applying dark diversity within one habitat type, e.g., as seen for grasslands (Riibak et al., 2015) may produce adequate results, however, when applying dark diversity across habitat types or broad environmental gradients, correcting for these differences through a residual dark diversity measure may provide more interpretable results.

With global biodiversity rapidly disappearing, it is vital to understand the drivers of biodiversity to prioritize conservation and make management more efficient. In this study, besides the ecospace position variables, competition seems to be the greatest driver of plant richness. Conservation management focusing 
on intermediate disturbance such as grazing can disrupt competitive communities making room for more species. Besides ecospace position, organic carbon was the most important variable for both dark diversity measures indicating that advanced succession and possibly temporal continuity may increase completeness or decrease dark diversity. Examining the influencing factors of different measures of biodiversity can lead to better decision-making in the future conservation of the world's biodiversity.

\section{Acknowledgements}

We sincerely thank Aage V. Jensen Nature Fund for financial support to CF, AKB, JM, LD, KC and JV for the project "Dark Diversity in nature management". The biowide project and REJ was supported by a grant from the Villum Foundation (VKR-023343). MP has been supported by the Estonian Ministry of Education and Research (IUT20-29), and the European Regional Development Fund (Centre of Excellence EcolChange).The authors declare no conflict of interest.

\section{References}

Aning, J. V. 2017. Diversity and completeness of north american mammal assemblages. M.Sc., Utrecht University.

Bartelheimer, M. \& Poschlod, P. 2016. Functional characterizations of e llenberg indicator values-a review on ecophysiological determinants. Functional ecology, 30, 506-516.

Bates, D., Sarkar, D., Bates, M. D. \& Matrix, L. 2007. The lme4 package. $R$ package version, $2,74$.

Beals, E. W. 1984. Bray-curtis ordination: An effective strategy for analysis of multivariate ecological data. In: Macfadyen, A. \& Ford, E. D. (eds.) Advances in ecological research. Academic Press.

Bello, F., Fibich, P., Zelený, D., Kopecký, M., Mudrák, O., Chytrý, M., Pyšek, P., Wild, J., Michalcová, D., Sádlo, J., Šmilauer, P., Lepš, J. \& Pärtel, M. 2016. Measuring size and composition of species pools: A comparison of dark diversity estimates. Ecology and Evolution, 6, 4088-4101. doi: doi:10.1002/ece3.2169.

Bennett, J. A., Riibak, K., Kook, E., Reier, Ü., Tamme, R., Guillermo Bueno, C. \& Pärtel, M. 2016. Species pools, community completeness and invasion: Disentangling diversity effects on the establishment of native and alien species. Ecology letters, 19, 1496-1505. 
Boussarie, G., Bakker, J., Wangensteen, O. S., Mariani, S., Bonnin, L., Juhel, J.-B., Kiszka, J. J., Kulbicki, M., Manel, S. \& Robbins, W. D. 2018. Environmental DNA illuminates the dark diversity of sharks. Science advances, 4, eaap9661.

Brunbjerg, A. K., Bruun, H. H., Broendum, L., Classen, A. T., Fog, K., Froeslev, T. G., Goldberg, I., Hansen, M. D. D., Hoeye, T. T., Laessoee, T., Newman, G., Skipper, L., Soechting, U. \& Ejrnaes, R. 2017a. A systematic survey of regional multitaxon biodiversity: Evaluating strategies and coverage. bioRxiv, 158030. doi: 10.1101/158030.

Brunbjerg, A. K., Bruun, H. H., Dalby, L., Classen, A. T., Fløjgaard, C., Frøslev, T. G., Hansen, O. L. P., Høye, T. T., Moeslund, J. E. R., Svenning, J.-C. \& Ejrnæs, R. in prep. Multitaxon inventory reveals highly consistent biodiversity responses to ecospace variation.

Brunbjerg, A. K., Bruun, H. H., Dalby, L., Fløjgaard, C., Frøslev, T. G., Høye, T. T., Goldberg, I., Læssøe, T., Hansen, M. D. \& Brøndum, L. 2018. Vascular plant species richness and bioindication predict multi $\square$ taxon species richness. Methods in Ecology and Evolution.

Brunbjerg, A. K., Bruun, H. H., Moeslund, J. E., Sadler, J. P., Svenning, J.-C. \& Ejrnæs, R. 2017 b. Ecospace: A unified framework for understanding variation in terrestrial biodiversity. Basic and Applied Ecology, 18, 86-94.

Bråthen, K. A. \& Lortie, C. 2016. A portfolio effect of shrub canopy height on species richness in both stressful and competitive environments. Functional ecology, 30, 60-69.

Buchwald, E., Wind, P., Bruun, H. H., Møller, P. F., Ejrnæs, R. \& Svart, H. E. 2013. Hvilke planter er hjemmehørende i danmark? Flora \& Fauna, 118, 73-96.

Burnham, K. P. \& Anderson, D. R. 2002. Model selection and multi-model inference: A practical information-theoretic approach, New York, Springer.

Butchart, S. H., Walpole, M., Collen, B., Van Strien, A., Scharlemann, J. P., Almond, R. E., Baillie, J. E., Bomhard, B., Brown, C. \& Bruno, J. 2010. Global biodiversity: Indicators of recent declines. Science, 328, 1164-1168. 
Cam, E., Nichols, J. D., Sauer, J. R., Hines, J. E. \& Flather, C. H. 2000. Relative species richness and community completeness: Birds and urbanization in the mid-atlantic states. Ecological Applications, 10, 1196-1210. doi: doi:10.1890/1051-0761(2000)010[1196:RSRACC]2.0.CO;2.

Carmona, C. P., Szava-Kovats, R. \& Pärtel, M. 2019. Estimating probabilistic dark diversity based on the hypergeometric distribution. bioRxiv, 636753. doi: 10.1101/636753.

Connell, J. H. 1978. Diversity in tropical rain forests and coral reefs. Science, 199, 1302-1310. doi: 10.1126/science.199.4335.1302.

Connell, J. H. \& Slatyer, R. O. 1977. Mechanisms of succession in natural communities and their role in community stability and organization. The American Naturalist, 111, 1119-1144.

Cornell, H. V. \& Harrison, S. P. 2014. What are species pools and when are they important? Annual Review of Ecology, Evolution, and Systematics, 45, 45-67. doi: 10.1146/annurev-ecolsys-120213-091759.

Danish Nature Agency 2016. Vascular plants in denmark recorded under the the nationwide monitoring and assessment programme for the aquatic and terrestrial environments (novana). Occurrence dataset. 9.1 ed. Global Biodiversity Information Facility.

De Bello, F., Price, J. N., Münkemüller, T., Liira, J., Zobel, M., Thuiller, W., Gerhold, P., Götzenberger, L., Lavergne, S. \& Lep̌̌, J. 2012. Functional species pool framework to test for biotic effects on community assembly. Ecology, 93, 2263-2273.

Díaz, S., Settele, J., Brondízio, E., Ngo, H. T., Guèze, M., Agard, J., Arneth, A., Balvanera, P., Brauman, K., Butchart, S., Chan, K., Garibaldi, L., Ichii, K., Liu, J., Subramanian, S. M., Midgley, G., Miloslavich, P., Molnár, Z., Obura, D., Pfaff, A., Polasky, S., Purvis, A., Razzaque, J., Reyers, B., Chowdhury, R. R., Shin, Y.-J., Hamakers, I. V., Willis, K. \& Zayas, C. Summary for policymakers of the global assessment report on biodiversity and ecosystem services of the intergovernmental science-policy platform on biodiversity and ecosystem services. In: Carneiro Da Cunha, M., Mace, G. \& Mooney, H., eds. IPBES-7th Plenary, 6 May 20192019 Paris, France. Intergovernmental Science-Policy Platform on Biodiversity and Ecosystem Services.

Ejrnæs, R. \& Bruun, H. H. 2000. Gradient analysis of dry grassland vegetation in denmark. Journal of Vegetation Science, 11, 573-584. 
Ejrnæs, R., Petersen, A. H., Bladt, J., Bruun, H. H., Moeslund, J. E., Wiberg-Larsen, P. \& Rahbek, C. 2014. Biodiversitetskort for danmark: Udviklet $i$ samarbejde mellem center for makroфkologi, evolution og klima på københavns universitet og institut for bioscience ved aarhus universitet, Aarhus Universitet, DCE-Nationalt Center for Miljø og Energi.

Ellenberg, H., Weber, H. E., Düll, R., Wirth, V., Werner, W. \& Paulißen, D. 1991. Zeigerwerte von pflanzen in mitteleuropa. Scripta Geobotanica, 18, 1-248.

Ernst, W. H. O. 1990. Ecophysiology of plants in waterlogged and flooded environments. Aquatic botany, 38, 73-90.

Estrada, A., Márcia Barbosa, A. \& Real, R. 2018. Changes in potential mammal diversity in national parks and their implications for conservation. Current Zoology.

Fraser, L. H., Pither, J., Jentsch, A., Sternberg, M., Zobel, M., Askarizadeh, D., Bartha, S., Beierkuhnlein, C., Bennett, J. A. \& Bittel, A. 2015. Worldwide evidence of a unimodal relationship between productivity and plant species richness. Science, 349, 302-305.

Garnier, E., Cortez, J., Billès, G., Navas, M.-L., Roumet, C., Debussche, M., Laurent, G., Blanchard, A., Aubry, D. \& Bellmann, A. 2004. Plant functional markers capture ecosystem properties during secondary succession. Ecology, 85, 2630-2637.

Gijbels, P., Adriaens, D. \& Honnay, O. 2012. An orchid colonization credit in restored calcareous grasslands. Ecoscience, 19, 21-28.

Grime, J. P. 1979. Plant strategies and vegetation processes. Plant strategies and vegetation processes.

Grime, J. P., Hodgson, J. G. \& Hunt, R. 2014. Comparative plant ecology: A functional approach to common british species, Springer.

Lewis, R. J., Szava $\square$ Kovats, R., Pärtel, M. \& Evolution 2016. Estimating dark diversity and species pools: An empirical assessment of two methods. Methods in Ecology, 7, 104-113.

Lyashevska, O. \& Farnsworth, K. D. 2012. How many dimensions of biodiversity do we need? Ecological Indicators, 18, 485-492. doi: https://doi.org/10.1016/j.ecolind.2011.12.016.

Mccune, B. 1994. Improving community analysis with the beals smoothing function. Ecoscience, 1, 82-86. 
Moeslund, J. E., Brunbjerg, A. K., Clausen, K. K., Dalby, L., Fløjgaard, C., Juel, A. \& Lenoir, J. 2017. Using dark diversity and plant characteristics to guide conservation and restoration. Journal of Applied Ecology, 54, 1730-1741.

Münzbergová, Z. \& Herben, T. 2004. Identification of suitable unoccupied habitats in metapopulation studies using co $\square$ occurrence of species. Oikos, 105, 408-414.

Oksanen, J., Blanchet, F. G., Kindt, R., Legendre, P., Minchin, P. R., O’hara, R., Simpson, G. L., Solymos, P., Stevens, M. \& Wagner, H. 2017. Vegan: Community ecology package. R package version 2.4-3.

Paradis, E., Claude, J. \& Strimmer, K. 2004. Ape: Analyses of phylogenetics and evolution in r language. Bioinformatics, 20, 289-290.

Perelman, S. B., Chaneton, E. J., Batista, W. B., Burkart, S. E. \& León, R. J. C. 2007. Habitat stress, species pool size and biotic resistance influence exotic plant richness in the flooding pampa grasslands. Journal of Ecology, 95, 662-673. doi: 10.1111/j.1365-2745.2007.01255.x.

Pärtel, M. 2002. Local plant diversity patterns and evolutionary history at the regional scale. Ecology, 83, 2361-2366. doi: 10.2307/3071796.

Pärtel, M. 2014. Community ecology of absent species: Hidden and dark diversity. Journal of Vegetation Science, 25, 1154-1159.

Pärtel, M., Helm, A., Ingerpuu, N., Reier, Ü. \& Tuvi, E.-L. 2004. Conservation of northern european plant diversity: The correspondence with soil ph. Biological Conservation, 120, 525-531. doi: https://doi.org/10.1016/j.biocon.2004.03.025.

Pärtel, M., Szava-Kovats, R. \& Zobel, M. 2011. Dark diversity: Shedding light on absent species. Trends in Ecology and Evolution, 26, 124-128.

Pärtel, M., Szava-Kovats, R. \& Zobel, M. 2013. Community completeness: Linking local and dark diversity within the species pool concept. Folia Geobotanica, 48, 307-317.

Pärtel, M., Zobel, M., Öpik, M. \& Tedersoo, L. 2017a. Global patterns in local and dark diversity, species pool size and community completeness in ectomycorrhizal fungi. In: Tedersoo, L. (ed.) Biogeography of mycorrhizal symbiosis. Cham: Springer International Publishing. 
Pärtel, M., Öpik, M., Moora, M., Tedersoo, L., Szava-Kovats, R., Rosendahl, S., Rillig, M. C., Lekberg, Y., Kreft, H., Helgason, T., Eriksson, O., Davison, J., Bello, F., Caruso, T. \& Zobel, M. 2017b. Historical biome distribution and recent human disturbance shape the diversity of arbuscular mycorrhizal fungi. New Phytologist, 216, 227-238. doi: doi:10.1111/nph.14695.

R Core Team 2019. R: A language and environment for statistical computing 3.6.0 ed. Vienna, Austria: https://www.R-project.org/.

Riibak, K., Reitalu, T., Tamme, R., Helm, A., Gerhold, P., Znamenskiy, S., Bengtsson, K., Rosén, E., Prentice, H. C. \& Pärtel, M. 2015. Dark diversity in dry calcareous grasslands is determined by dispersal ability and stress $\square$ tolerance. Ecography, 38, 713-721.

Riibak, K., Ronk, A., Kattge, J. \& Pärtel, M. 2017. Dispersal limitation determines large $\square$ scale dark diversity in central and northern europe. Journal of Biogeography, 44, 1770-1780.

Ronk, A., De Bello, F., Fibich, P. \& Pärtel, M. 2016. Large-scale dark diversity estimates: New perspectives with combined methods. Ecology and Evolution, 6, 6266-6281. doi: doi:10.1002/ece3.2371.

Ronk, A., Szava $\square$ Kovats, R. \& Pärtel, M. 2015. Applying the dark diversity concept to plants at the european scale. Ecography, 38, 1015-1025.

Scott, C. E., Alofs, K. M. \& Edwards, B. A. 2011. Putting dark diversity in the spotlight. Trends in Ecology \& Evolution, 26, 263-264.

Stein, A., Gerstner, K. \& Kreft, H. 2014. Environmental heterogeneity as a universal driver of species richness across taxa, biomes and spatial scales. Ecology letters, 17, 866-880.

Tittensor, D. P., Walpole, M., Hill, S. L. L., Boyce, D. G., Britten, G. L., Burgess, N. D., Butchart, S. H. M., Leadley, P. W., Regan, E. C., Alkemade, R., Baumung, R., Bellard, C., Bouwman, L., BowlesNewark, N. J., Chenery, A. M., Cheung, W. W. L., Christensen, V., Cooper, H. D., Crowther, A. R., Dixon, M. J. R., Galli, A., Gaveau, V., Gregory, R. D., Gutierrez, N. L., Hirsch, T. L., Höft, R., Januchowski-Hartley, S. R., Karmann, M., Krug, C. B., Leverington, F. J., Loh, J., Lojenga, R. K., Malsch, K., Marques, A., Morgan, D. H. W., Mumby, P. J., Newbold, T., Noonan-Mooney, K., Pagad, S. N., Parks, B. C., Pereira, H. M., Robertson, T., Rondinini, C., Santini, L., Scharlemann, J. P. W., Schindler, S., Sumaila, U. R., Teh, L. S. L., Van Kolck, J., Visconti, P. \& Ye, Y. 2014. A 
mid-term analysis of progress toward international biodiversity targets. Science, 346, 241-244. doi: 10.1126/science.1257484.

476 Townsend, C. R., Scarsbrook, M. R. \& Dolédec, S. 1997. The intermediate disturbance hypothesis, refugia, 477 and biodiversity in streams. Limnology and oceanography, 42, 938-949.

478 Venables, W. N. \& Ripley, B. D. 2013. Modern applied statistics with s-plus, Springer Science \& Business Media.

Zobel, M. 1997. The relative of species pools in determining plant species richness: An alternative explanation of species coexistence? Trends in ecology \& evolution, 12, 266-269.

482 


\section{Tables}

485 Table 1. Explanatory variables, their affiliation to ecospace elements and their hypothesized association with 486 response variables. Question marks indicate that hypotheses are either ambiguous or unknown.

\begin{tabular}{llll}
\hline Explanatory variable & Ecospace dimension & Dark Diversity & Plant Richness \\
\hline Soil moisture index (SMI) & Position & $?$ & Unimodal \\
Soil fertility index (SFI) & Position & $?$ & Unimodal \\
Soil pH & Position & $?$ & Positive \\
Light & Position & $?$ & Positive \\
Litter & Expansion & Positive & Negative \\
Bare soil & Expansion & Negative & Positive \\
Organic carbon (OrgC) & Expansion & $?$ & $?$ \\
Organic matter & Expansion & $?$ & $?$ \\
Shrub height variation & Expansion & Negative & Positive \\
Canopy height variation & Expansion & Negative & Positive \\
Intensive field & Continuity & Positive & Negative \\
Natural landscape & Continuity & Negative & Positive \\
Temporal continuity & Continuity & Negative & Positive \\
Competition (Grime C) & Interactions & Positive & Negative \\
\hline
\end{tabular}


489

490

491

492

493

\begin{tabular}{|c|c|c|c|c|}
\hline Ecospace & Variables & $\mathrm{DD}$ & Residual DD & Plant richness \\
\hline & Intercept & $5.090^{* * * *}(0.014)$ & $-0.000(0.136)$ & $3.762^{* * *}(0.081)$ \\
\hline Position & Soil moisture index (SMI) & $-0.020^{*}(0.011)$ & n.s. & $0.190^{* * *}(0.054)$ \\
\hline Position & $\mathrm{SMI}^{2}$ & $-0.025^{* *}(0.012)$ & n.s. & $0.150^{* * *}(0.053)$ \\
\hline Position & Soil fertility index (SFI) & $0.069^{* * * *}(0.011)$ & n.s. & $0.233^{* * *}(0.055)$ \\
\hline Position & $\mathrm{SFI}^{2}$ & n.s. & n.s. & $-0.145^{* * *}(0.029)$ \\
\hline Position & Soil pH & $0.030^{* * * *}(0.009)$ & n.s. & $0.269^{* * *}(0.071)$ \\
\hline Position & Soil $\mathrm{pH}^{2}$ & n.s. & n.s. & $-0.060^{*}(0.034)$ \\
\hline Position & Light & $-0.042^{* * *}(0.010)$ & n.s. & $0.102(0.066)$ \\
\hline Position & Light $^{2}$ & n.s. & n.s. & $-0.086^{*}(0.047)$ \\
\hline Expansion & Litter $(\log )$ & n.s. & n.s. & $-0.105^{*}(0.056)$ \\
\hline Expansion & Organic carbon (OrgC) & $-0.045^{* * *}(0.011)$ & $-0.465^{* * *}(0.137)$ & $-0.126^{* *}(0.050)$ \\
\hline Expansion & Bare soil & n.s. & n.s. & $-0.079(0.050)$ \\
\hline Expansion & Shrub height variation & n.s. & n.s. & $0.161^{* * *}(0.048)$ \\
\hline Interaction & Competition (Grime C) & $0.037^{* * * *}(0.009)$ & n.s. & $-0.192^{* * *}(0.048)$ \\
\hline Continuity & Natural Landscape & n.s. & $-0.326^{* *}(0.137)$ & n.s. \\
\hline & Multiple $\mathrm{R}^{2}$ & 0.65 & 0.14 & 0.65 \\
\hline
\end{tabular}

Table 2. Regression results for dark diversity (DD) using Poisson, residual dark diversity for habitat types using ordinary least squares and plant species richness (PlantRich) with negative binomial. $\mathrm{R}^{2}$ is calculated as 1-(model deviance/model null deviance) for dark diversity and plant species richness for residual dark diversity (DD) we report the multiple $\mathrm{R}^{2}$. Parentheses gives the standard errors. $* \mathrm{p}<0.1 ; * * \mathrm{p}<0.05 ; * * * \mathrm{p}<0.01$. 
bioRxiv preprint doi: https://doi.org/10.1101/685040; this version posted June 27, 2019. The copyright holder for this preprint (which was not certified by peer review) is the author/funder, who has granted bioRxiv a license to display the preprint in perpetuity. It is made available under aCC-BY-NC-ND 4.0 International license.

\section{Figures}

(a)

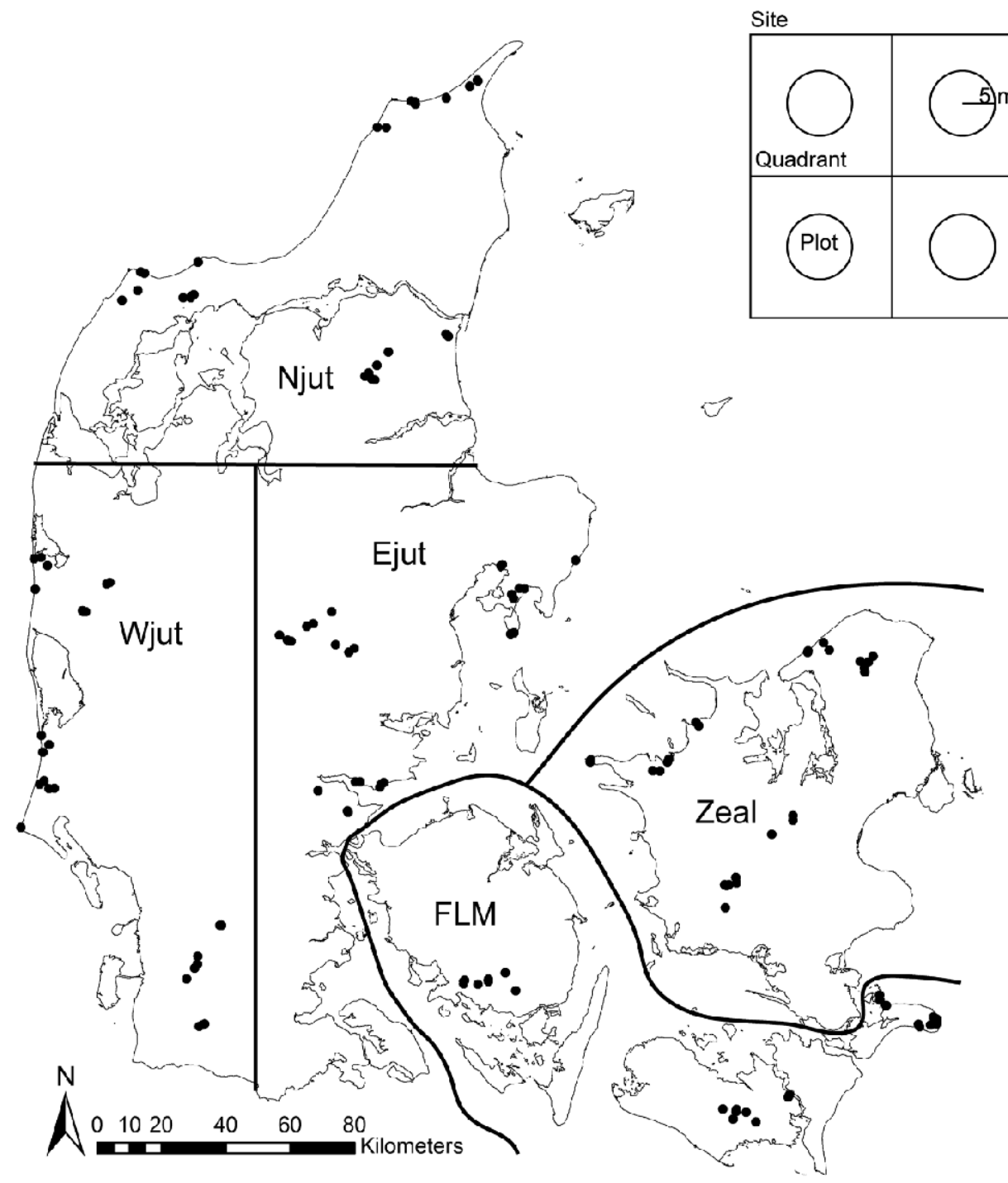

498 Figure 1. (a) Map of Denmark showing the 130 surveyed sites and the regions. (b) $40 \mathrm{~m} \times 40 \mathrm{~m}$ site with the four quadrants and $5 \mathrm{~m}$ circle plots. 
$\begin{array}{lllll}100 & 150 & 200 & 250 & 300\end{array}$
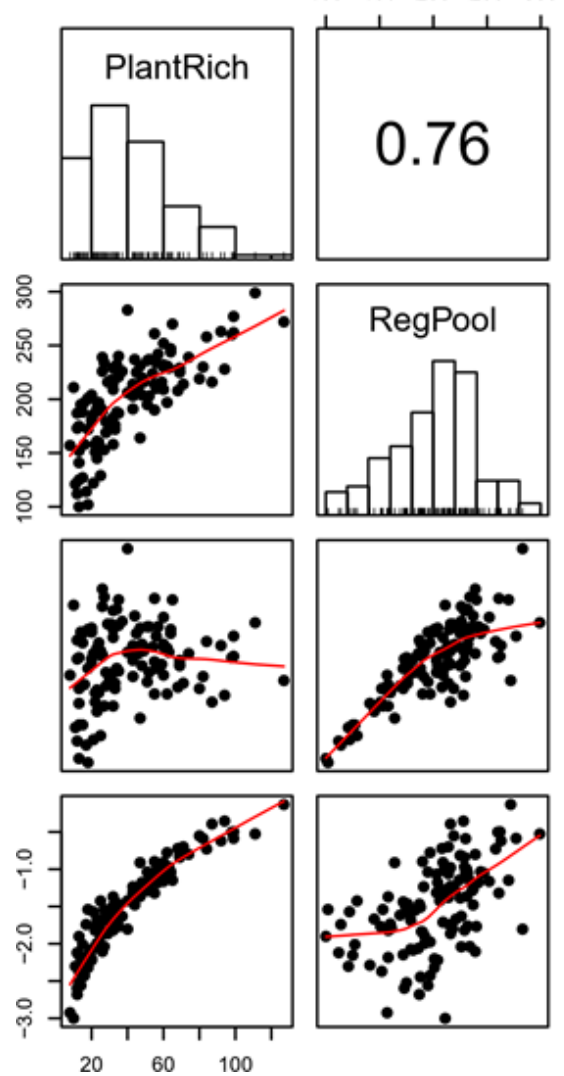
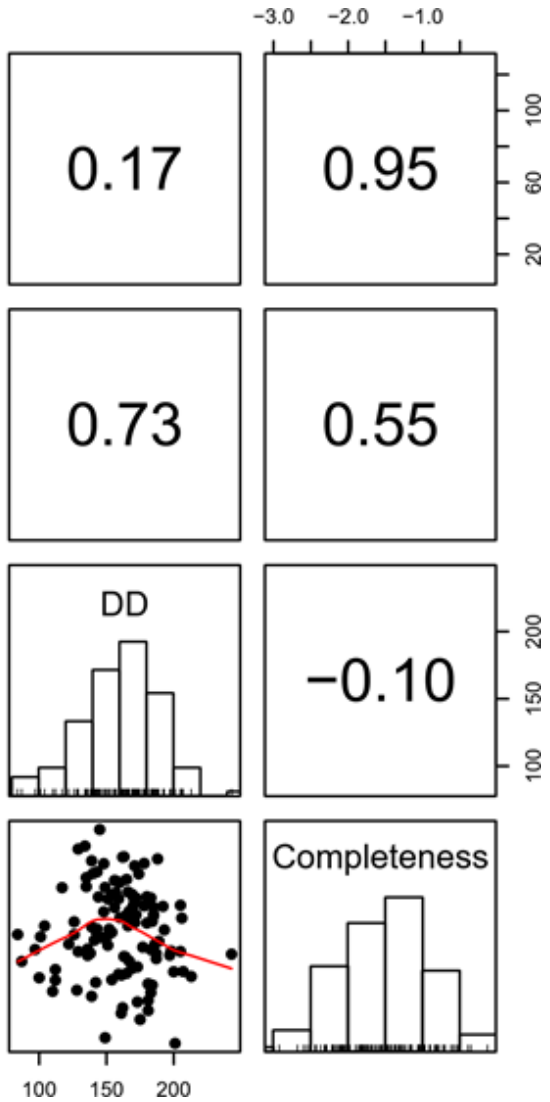

Figure 2. Spearman rank correlations and dot plots of site regional pool, plant species richness, dark diversity and completeness. The red line in the plot shows a loess smoothing line. 

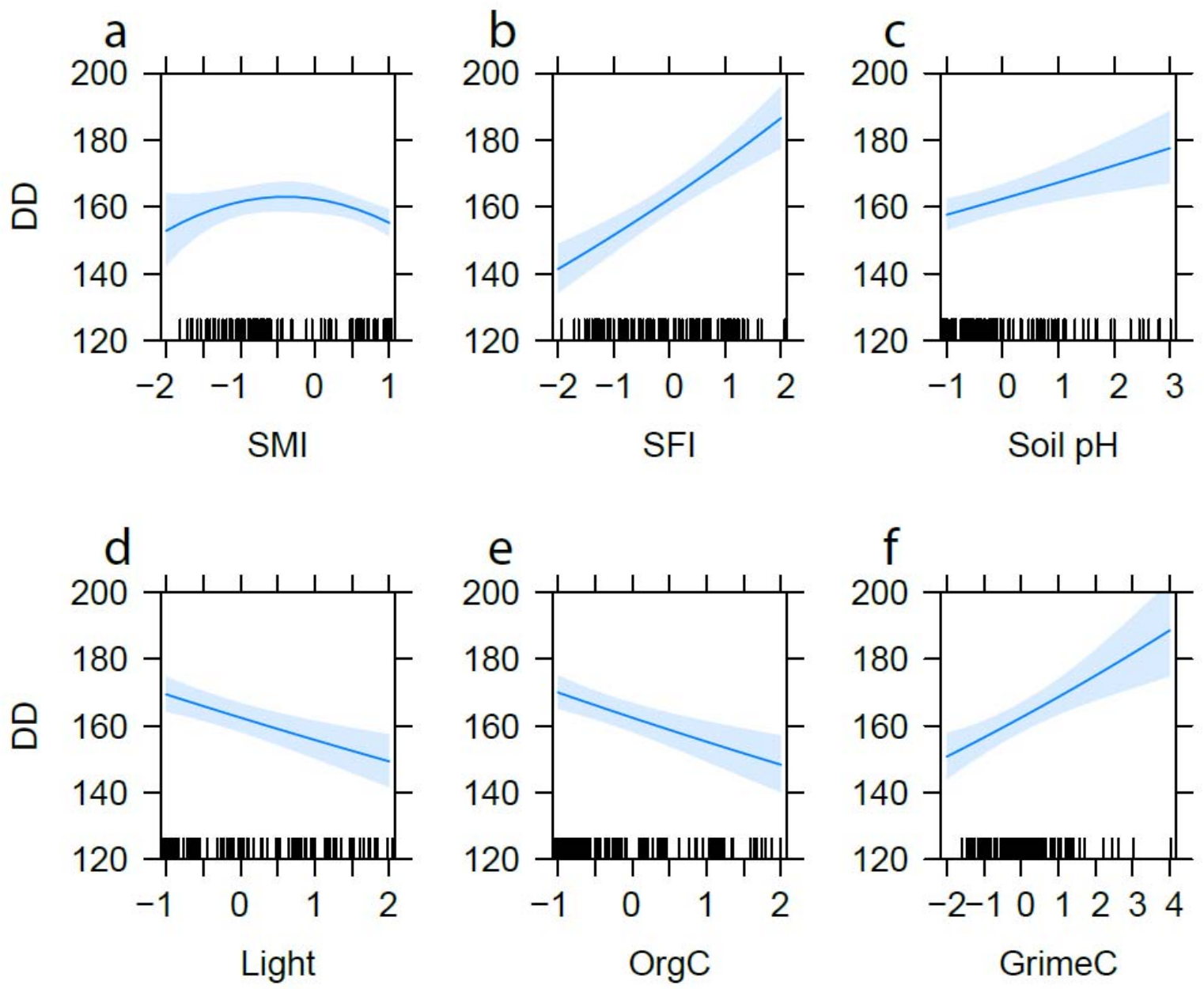

504 Figure 3. Parameter estimates with $95 \%$ confidence intervals from the significant environmental variables predicting overall dark diversity. Relationships between the dark diversity and (a) soil moisture index (SMI), (b) soil fertility index, (c) soil pH, (d) light, (e) organic matter, and (f) competition (GrimeC). Y-axis is truncated. 

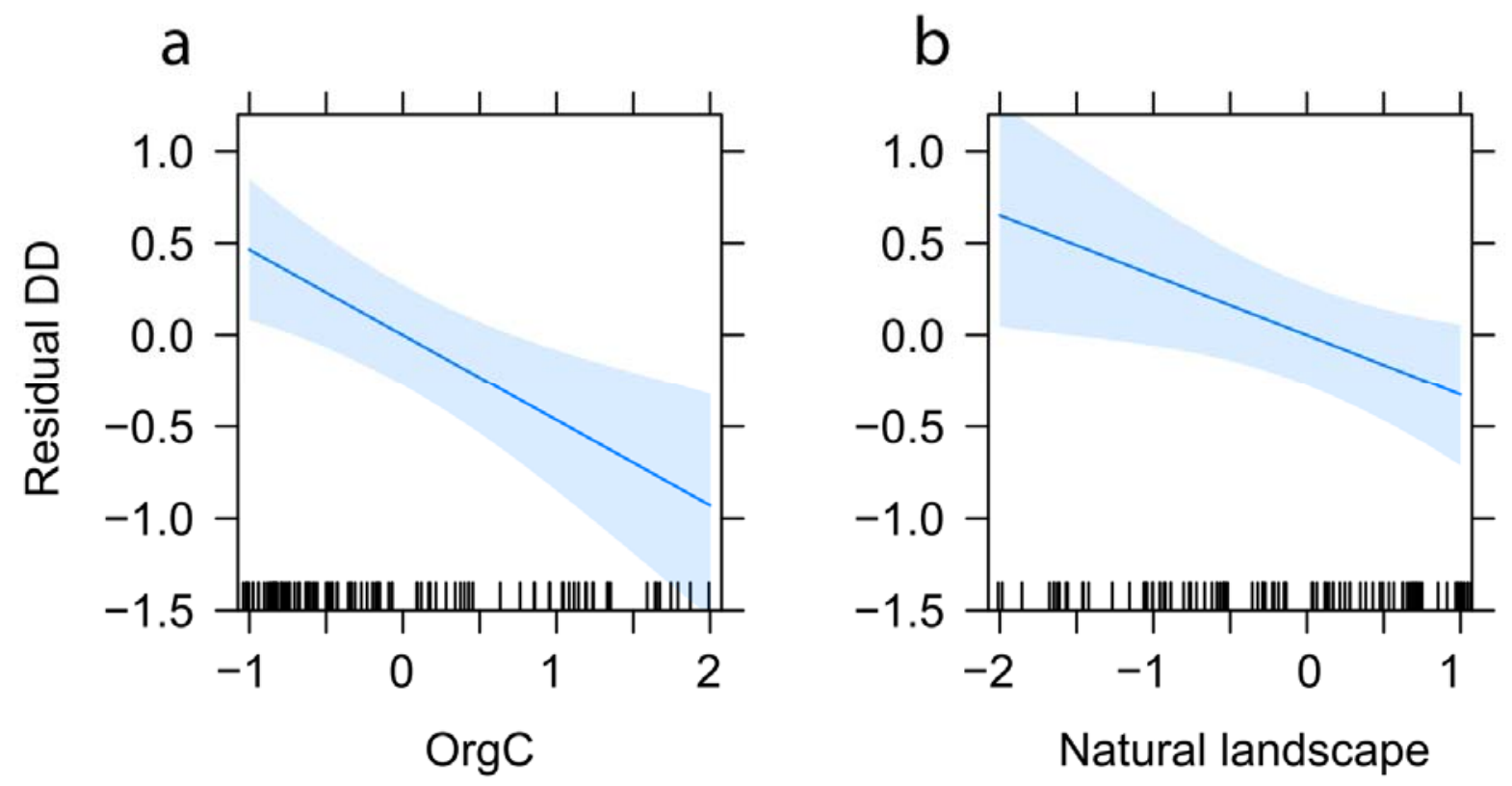

Figure 4. Parameter estimates with $95 \%$ confidence intervals from the significant environmental variables

510 predicting residual dark diversity for habitat types. Relationships between residual dark diversity and (a)

511 organic carbon $(\mathrm{OrgC})$, and (b) natural landscape. 
a
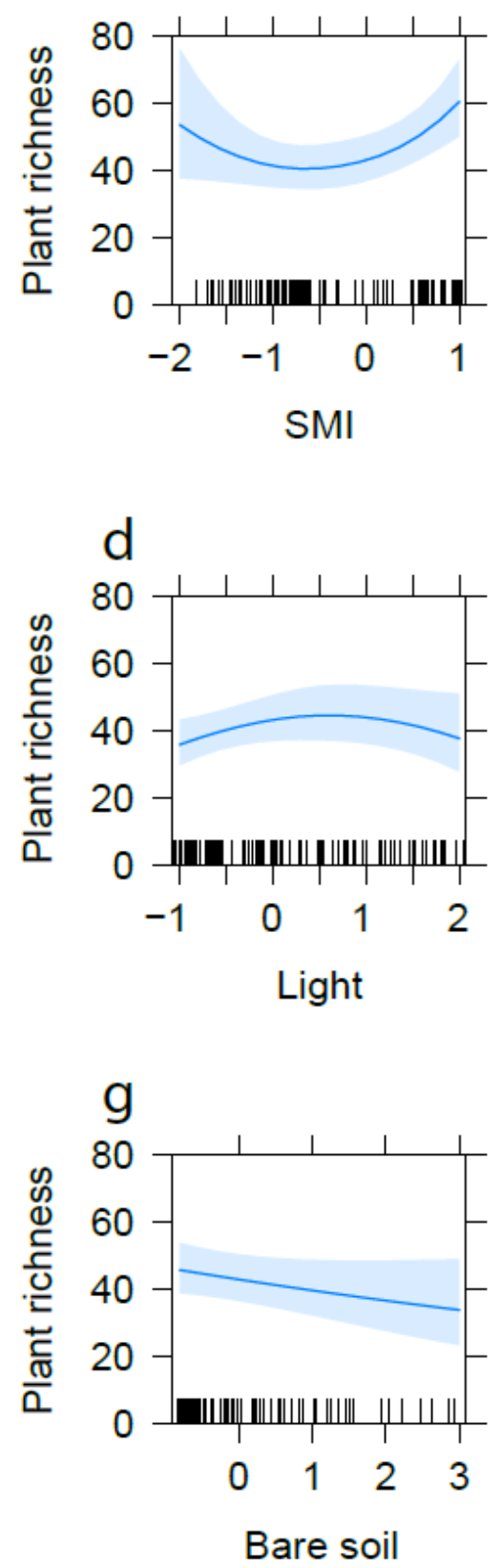

b

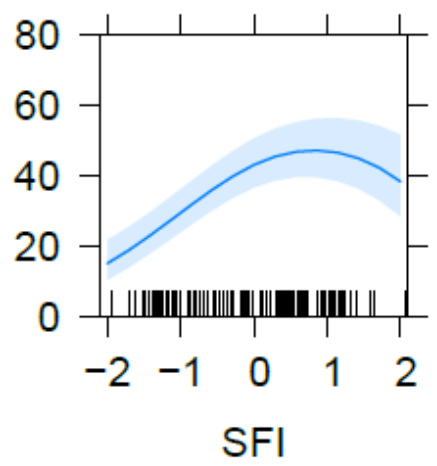

e

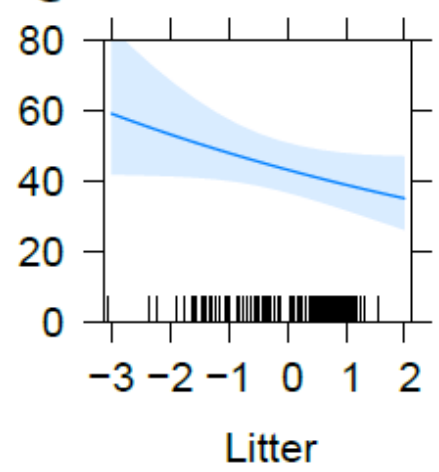

$\mathrm{h}$

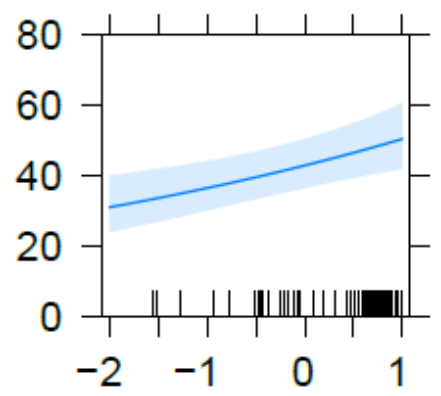

Shrub height var
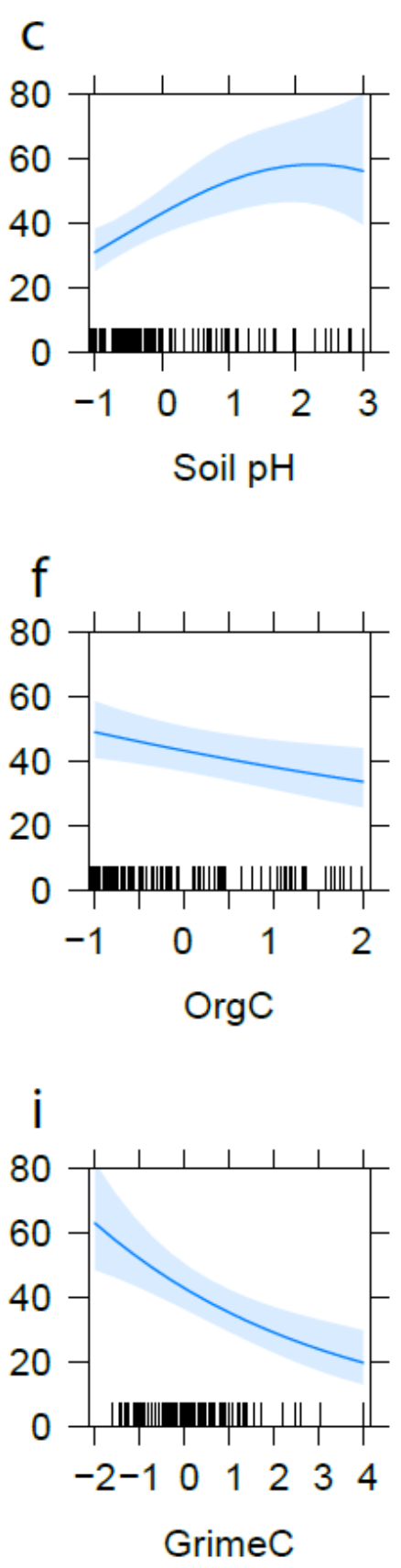

Figure 5. Parameter estimates with $95 \%$ confidence intervals from the significant environmental variables

514 predicting plant species richness. Relationships between the plant species richness and (a) soil moisture 515 index (SMI), (b) soil fertility index (SFI) (c) soil pH, (d) litter mass, (f) organic carbon, (g) bare soil, (h) shrub height variation, and (i) competition (GrimeC). 